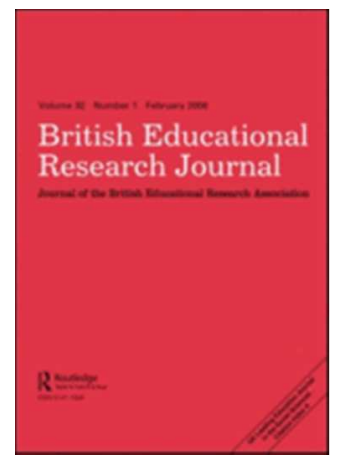

\title{
Regulating the student body/ies: university policies and student parents
}

\begin{tabular}{|c|l|}
\hline Journal: & British Educational Research Journal \\
\hline Manuscript ID & CBER-2015-0199.R2 \\
\hline Manuscript Type: & Original Paper \\
\hline \hline Keywords: & $\begin{array}{l}\text { student parents, Higher Education < Formal Learning Contexts, widening } \\
\text { participation, England }\end{array}$ \\
\hline Abstract: & $\begin{array}{l}\text { Despite a cultural positioning of care at the margins of academia, student } \\
\text { parents now represent a significant proportion of the higher education } \\
\text { population in England and in other Western countries. Research shows } \\
\text { that, beyond the diversity of their experiences, time, childcare, financial, } \\
\text { and well-being related issues prevail among them. However, extant } \\
\text { research concentrates mostly on the experiential level - often alluding to } \\
\text { policies, yet rarely focusing on their role in compounding or easing the } \\
\text { issues experienced by this group. Using the lens of sociological and } \\
\text { feminist theories and drawing on data collected in ten English higher } \\
\text { education institutions, this article addresses this dearth of research. It does } \\
\text { argue that, through policies which overall tend to be geared towards child- } \\
\text { free students, universities reinforce discourses normalising the figure of the } \\
\text { 'care-free' student and ultimately contribute to the marginalisation of } \\
\text { student parents within higher education. However, despite the prevalence } \\
\text { of such policies, attempts to redefine the student body/ies in more } \\
\text { inclusive ways are also identified, suggesting a partial transformation of } \\
\text { academic cultures. Through its identification and discussion of various } \\
\text { institutional policy approaches to student parents, this paper attempts to } \\
\text { further the development of a sociology linking areas of society and of } \\
\text { people's lives (in this case, care and academia) which have historically } \\
\text { been constructed as separate, and to understand how institutional policies } \\
\text { reproduce or challenge this binary. }\end{array}$ \\
\hline \hline
\end{tabular}

\section{SCHOLARONE ${ }^{\text {Tw }}$ \\ Manuscripts}




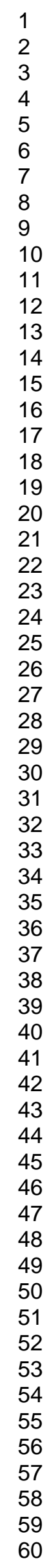

25

26

28

29

32

33

34

35

36

38

39

40

41

43

44

45

46

47

48

50

51

52

54

55 
Regulating the student body/ies: university policies and student parents

1

2

3

4

5

6

7

8

9

10

11

12

13

14

15

16

17

18

19

20

21

22

23

24

25

26

27

28

29

30

31

32

33

34

35

36

37

38

39

40

41

42

43

44

45

46

47

48

49

50

51

52

53

54

55

56

57

58

59

60 


\title{
Regulating the student body/ies: university policies and student parents
}

\begin{abstract}
Despite a cultural positioning of care at the margins of academia, student parents now represent a significant proportion of the higher education population in England and in other Western countries. Research shows that, beyond the diversity of their experiences, time, childcare, financial, and wellbeing related issues prevail among them. However, extant research concentrates mostly on the experiential level - often alluding to policies, yet rarely focusing on their role in compounding or easing the issues experienced by this group. Using the lens of sociological and feminist theories and drawing on data collected in ten English higher education institutions, this article addresses this dearth of research. It does argue that, through policies which overall tend to be geared towards childfree students, universities contribute to the marginalisation of student parents within higher education. However, despite the prevalence of such policies, attempts to redefine the student body/ies in more inclusive ways are also identified, suggesting a partial transformation of academic cultures. Through its identification and discussion of various institutional policy approaches to student parents, this paper attempts to further the development of a sociology linking areas of society and of people's lives (in this case, care and academia) which have historically been constructed as separate, and to understand how institutional policies reproduce or challenge this binary.
\end{abstract}

Keywords: student parents; higher education; widening participation; England 


\section{Introduction}

In the UK and the rest of the 'global North', higher education (HE) has considerably expanded and diversified since the mid-1950s (Archer et al, 2003; Office for National Statistics, 2013). However, whether this process has been associated with a democratisation of HE and the redefinition of academic cultures remains a contentious point (Shavit et al, 2007). Indeed, sociologists have highlighted the persistence in HE of divides based on social class, gender and ethnicity and the continued association between academic excellence and the canonical figure of the White, middleclass, male and 'unencumbered' ${ }^{1}$ student (Archer et al, 2003; Leathwood \& O'Connell, 2003; Leathwood \& Read, 2009; Maher \& Tetreault, 2007). HE spaces, pedagogical practices and students' experiences have been, and continue to be, shaped by hegemonic discourses of teaching and learning which are classed, raced and gendered, from the point of entry into HE territory to the micropolitics of the classroom (Burke, 2013). 'Non traditional' students (i.e. those who are not White, 'young,', middle-class, able-bodied, childless or with standard A level qualifications; Webb, 1997) have entered academia but concentrate in its less prestigious and rewarding segments. For example, while women represent the majority of HE students in the UK and in many other parts of the global North, they concentrate at undergraduate level, in the less prestigious institutions and in subjects whose rewards are the most uncertain (European Commission, 2009; Leathwood \& Read, 2009). Similarly, research highlights the extent of the overt and pervasive discrimination to which women, particularly mothers, and Black and Minority Ethnic staff are subjected to in academia (Armato, 2013; Leathwood et al, 2009; Savigny, 2014; Schell, 2002; Wennerås \& Wold, 1997), as also evidenced by a number of recent events echoed in the media (e.g., Bates, 2014; Ellis-Petersen, 2014; Young-Powell, 2014). The association between academic excellence and White, middle-class masculinities is also evidenced by the disproportionate allocation of markers of esteem to those endorsing these identities, from sitting on research committees, editorial boards and evaluation panels to being a recipient of the Nobel Prize (Rossiter, 1982; Schiebinger, 1992). This has led some to reject a view of academic cultures as inclusive and to instead describe these as 'careless' (Lynch, 2010), lacking 'any intrinsic ethics of care' (Reay, 2000: 19), or even 'toxic' (Gill, 2009).

As argued by Alsop and colleagues, Western culture has a long history of excluding women from education. It used to be commonly believed that 'if women engaged in intellectual pursuits their reproductive capacities would be compromised' (2008: 630). The $17^{\text {th }}$ century is usually considered a milestone in the linkage of academia with the figure of the 'bachelor boy' (Edwards, 1993; HintonSmith, 2012). The Cartesian rationalist ideals which shaped the emergence of modern science drew on

\footnotetext{
${ }^{1}$ The notion of 'unencumbered', as used in this paper, refers to individuals without major caring responsibilities. This includes for example students who are childfree, as well as those who are able to rely on (usually female) others to free them from care work.

${ }^{2}$ In the UK, undergraduate students who are over 21 when they enrol at university are identified as 'mature' students.
} 
the mind/body, object/subject, public/private, and rational/emotional dyads (Descartes, 1996 [1641]). As Bordo claims, '.....while dualism runs deep in our tradition, it is only with Descartes that body and mind are defined in terms of mutual exclusivity' (1987: 93). However, the mind/body and other dichotomies have been described as fallacies as the disembodied mind, like the 'universal' citizen of the philosophy of Enlightenment, actually conceals a White masculine body, which, because it is unmarked and is taken to be the norm, remains invisible (Delphy, 2010; Héritier, 2002; Puwar, 2004).

The rational subject of academic knowledge continues to be constructed as masculine (Lloyd, 1993; Walkerdine, 1988), with his identity produced through a denial of emotions, domestic affairs, as well as physicality and bodily matters (Ahmed, 1998; Beard et al, 2007; Braidotti, 1991; Leathwood \& Hey, 2009). This has led to the exclusion of those usually associated with these features, including women, of which particularly mothers, traditionally relegated to domestic realms. For example, while both the UK and France created their first university during the 12th century, it took another seven centuries for these institutions to accept women, and even longer for them to be able to receive a degree. Lécuyer (2005) recalls how, towards the end of the 19th century, in France, l'étudiante referred to a young woman in a relationship with a male student (l'étudiant) rather than to its female equivalent.

However, while Cartesian dualisms still permeate academic cultures and Western conceptions of scientific and other academic knowledge, university spaces now accommodate a more diverse crowd. Women, Black and Minority Ethnic, working-class and mature students constitute a significant presence on campuses across the global North, and so do student parents. While there is a dearth of statistical data on this group, a NUS survey suggests that a third of those studying in the Further and Higher Education sector in England and Wales care for a dependant (NUS, 2009), while the Student Income and Expenditure Survey data reveal that respectively $8 \%$ and $36 \%$ of English-domiciled fulltime and part-time students are parents (Johnson et al, 2009). In the context of a stratified HE sector, these figures are likely to hide some significant variations, depending on the type of institution, the subject and the mode of study. Extant data suggest that student parents are more likely than their childfree counterparts to study vocational and professional subjects and to adopt a part-time mode of study (NUS, 2009). Because they often do not relocate to attend university and because of their overrepresentation among other groups of non traditional students, ${ }^{3}$ it also seems reasonable to assume that they concentrate in the post-1992 sector.

With this context in mind, this article explores the role of university policies in compounding the experiences of student parents - a group who remains under-researched. It considers whether (and, if so, how) institutional policies normalise the figure of the 'carefree' student and simultaneously

\footnotetext{
${ }^{3}$ Student parents are more likely than their childfree counterparts to be 'mature', female and from Black and Minority Ethnic groups (NUS, 2009).
} 
marginalise student parents within HE. Starting with an explanation of the theoretical and methodological approaches underpinning this paper, the article then proceeds with a discussion of the positioning of student parents and children within/outside academic sites. It then moves to a consideration of three institutional approaches to student parents (a 'universal', a 'targeted' and a 'mainstreaming' approach), reflecting on their benefits and limitations and, more broadly, on how institutional university policies regulate (the) student body/bodies through their normalisation and/or their resistance to the figure of the childfree student. Through its identification and discussion of various institutional policy approaches to student parents, this paper attempts to further the development of a sociology linking areas of society and of people's lives (in this case, care and academia) which have historically been constructed as separate, and to understand how institutional policies reproduce or challenge this binary.

\section{Methodological and theoretical framework}

The data discussed in this article originate from a research project funded by the Nuffield Foundation, as part of its Student Parents' and Women's Education research programme (AUTHOR). The fieldwork was conducted in ten English universities, in various regions and with diverse statuses. ${ }^{4} \mathrm{~A}$ desk search preceded the fieldwork phase to gain some general background information and to map the provision in place in relation to student parents in each case study institution, with some of this information then used as a probe during the interview phase. Following that, 20 semi-structured interviews were conducted with university staff based in Student Services (reflecting the focus of the original study on the relationship between institutional policies and the experiences of student parents). In each university, attempts were made to interview one member of staff working with students in a support role and another member of staff working in a more managerial position. Semistructured interviews were also conducted with 40 student parents, who also completed a short questionnaire, to collect information on their socio-demographic background and to gain a general sense of how satisfied they were with their experience of university. Once consent had been gained and access negotiated at institutional level, a call for volunteers willing to be interviewed was circulated in each participating university. The research team endeavoured to interview a diverse sample of students in terms of gender, socio-economic and ethnic backgrounds, age, level and mode of study, subject and family circumstances, although this was met with some mitigated success (e.g., only two male students were interviewed, despite repeated attempts to achieve a more gender-balanced sample). All participating students had in common to be a parent to at least one child under the age of

\footnotetext{
${ }^{4}$ Out of the ten participating institutions, six were post-1992 universities, i.e. institutions which, in England, have gained university status that year. 'Non traditional' students tend to concentrate in these universities, which also tend to be considered less prestigious than their pre-1992 counterparts. Five institutions were based in the South of England, three in the North and two in the East.
} 
12 living in their home. The interviews were recorded and transcribed by a professional agency and imported into a qualitative data analysis software package (NVivo). The transcripts were subjected to a thematic and discourse analysis (see also AUTHOR), with key themes derived from the original research questions, from the interview questions, and from the repeated readings of the transcripts. The analyses developed in this paper rely primarily on the information relating to university policies and provision which have been collected through the desk search and the interviews with staff and students. However, the paper only draws on student parents' narratives insofar as they shed light on the 'cared' effects of specific types of policies (for a more comprehensive analysis of student parents' experiences, see AUTHOR). Likewise, while staff practices and representations are important in producing care regimes which are more or less inclusive of student parents and other carers, this paper focuses on institutional policies rather than staff's views and practices which are discussed elsewhere (see AUTHOR).

The theoretical framework draws on sociological understandings of work and education informed by feminist theories (Crompton, 1999; Le Feuvre, 2002). National policies and cultures (the macro-social level), institutional policies and cultures (meso-social) and individual biographies (micro-social) are understood as interacting in their production of the social world (Crompton, 1999). This interaction is complex and it is acknowledged that institutional policies, the focus of this paper, do not determine people's lives as they only represent one of many influences and are subject to negotiation and resistance (Foucault, 1969). Rather, institutional and national policies are conceptualised as creating a terrain allowing particular scripts to emerge. The use of the concepts of 'care order', 'care regime' and 'care practice' reflects this multi-level conceptualisation of the social world and draws on earlier distinctions between 'gender order', 'gender regime' and 'gender practice' (Connell, 1987; Matthews, 1984). 'Care orders', 'care regimes' and 'care practice' are gendered (as well as classed and raced), thus are not used in replacement of the notion of gender order and gender regime but in articulation with these and other power relationships (Lynch et al, 2009). This set of concepts allows us to differentiate between the care and gender arrangements in place at the macro level ('order'), at the meso level ('regime') and at the micro level ('practice') and to understand the multi-level social production and negotiation of relationships of care and gender. This conceptualisation is also helpful in that it constructs gender and care regimes as socio-historically located dynamic arrangements, which however present a relative level of stability overtime (Connell, 1987). Reflecting the positioning of student parents at the nexus of several spheres of the social world (education, care and other forms of paid and unpaid work) and relationships of power (gender, class, and race, among others), this paper is also informed by sociological studies of non traditional HE students, with specific reference to feminist analyses of English-speaking 'Northern' contexts, due to the culturally specific nature of HE (e.g., Alsop et al, 2008; Archer et al, 2003; Burke, 2013; Crozier et al, 2008; Gill, 2009; Leathwood \& Read, 2009; Lynch, 2006, 2010; Read et al, 2003; Reay, 2003). 
This scholarship has led to the production of a voluminous body of knowledge about the effects of widening participation on various groups of students and on the benefits as well as the ambivalences associated with being a non traditional student. However, parental status is often peripheral to these discussions, despite the influence it bears on individuals', particularly women's, educational and career trajectories (Crompton, 1999). As argued elsewhere (AUTHOR), while earlier studies have explored the experiences of mature students and/or student mothers (e.g., David et al, 1993; Edwards, 1993; Morley \& Walsh, 1996), it is only in the late noughties that 'student parent' has emerged as a category in its own right (Brooks, 2012, 2013, 2015; Danna Lynch, 2008; Hinton-Smith, 2012; Marandet \& Wainwright, 2009, 2010). This body of work has shown how the multiple and intersectional positioning of student parents provides an explanation for the time, childcare, financial, well-being and retention issues which prevail among this group. However, while this work often alludes to the impact of national and institutional policies on student parents' experiences, its focus remains on the experiential or micro-social rather than on the institutional or meso-social level.

\section{Parents, children and pregnant bodies: invisible others in academia?}

As highlighted in the introduction to this paper, academia has a long history of excluding certain groups. The Cartesian mind/body and other binaries which have shaped the emergence of modern science and educational institutions are powerful, having successfully transformed emotional, bodily and domestic matters in illegitimate concerns within institutional sites of knowledge production and, ultimately, having contributed to the historic exclusion of women, children and other non-privileged groups.

Academic cultures have undertaken a radical transformation since Descartes wrote his Meditations on First Philosophy and other essays. Organisational structures, relationships of power, pedagogies and epistemological paradigms all have deeply reconfigured. The work of Feminist, Black and other Critical theorists (Bowles \& Duelli-Klein, 1983; Freire, 1972; hooks, 1994) vividly illustrates the resistance to the old frameworks, with their challenge to the more traditional curriculum contents and pedagogical practices, and their post-positivist redefinition of what qualifies as academic knowledge. These days, many programmes of studies are available part-time or through distance learning, acknowledging the commitments that some students have outside academia. Some universities have also been described as enclaves for non traditional groups of students, as in the case of the post-1992 sector in the UK, although this pattern is not unproblematic as these institutions are usually associated with lower levels of prestige and returns from getting a degree, reflecting the integration at the margins of these groups (Archer et al, 2003). 
The context against which the lives of student parents unfold and institutional policies are implemented is characterised by two prominent discourses, which coincide in marking student parents as 'others' in academia. Since the 1980s, a discourse of the 'entrepreneurial' or 'managerial university' (Nikunen, 2014), characterised by the application of the principles of new public management to the HE sector has prevailed. As a result, universities have become 'powerful consumer-oriented corporate networks' (Lynch, 2006: 1). The importation of corporate managerial models and the search for performativity have led to the multiplication of performance indicators and quality assurance measures, and to a focus on measurable outputs, with HE also being redefined in more instrumental terms, as a tool serving the knowledge economy (Gill, 2009; Olssen \& Peters, 2005). Simultaneously, although levels of public investment in widening participation remain significant, concerns for social justice have overtime become increasingly driven by market imperatives and the implementation of the equality agenda devoluted at institutional level (Burke, 2013; Riley, 1994).

It has been claimed that relations of dependency and interdependency, feelings and emotions have been played down by liberal and neoliberal ideologies (Fraser \& Gordon 1997; Grummell et al, 2009; Lynch et al, 2009). In particular, Lynch argues that the advent of neo-liberal regimes of governmentality in HE has worsened its 'careless' nature (Lynch, 2006) and that carelessness has become 'deeply interwoven with the commerce of HE markets' (2010: 59). Students have been repositioned as economic rational subjects and, like university staff, simultaneously subjected to increased surveillance (Gill, 2009). The intensification of academic work under neo-liberalism is also a well-documented phenomenon (Calvert et al, 2011), which affects postgraduate students - a group often expected to operate as 'productive employees' (Macoun \& Miller, 2014). This managerial culture of HE has been described as masculinist as the characteristics of the ideal manager are broadly associated with hegemonic forms of masculinity (Morley, 2013) and as a culture of long hours, worldwide geographical mobility and short-time availability has developed (Grummel et al, 2009). This model is often out of reach for women, particularly mothers, as they continue to undertake most care work, both inside and outside academia. As summarised by Grummell et al, 'the new capitalist academy... imposes expectations of performativity that only a care-less worker can fully satisfy' (2009: 192).

Like academia, parenting has been described as a 'greedy institution' (Coser, 1974). Both appear to be time rather than task-driven and always leave room for bettering one's own (academic and parenting) work (Edwards, 1993; Hinton-Smith, 2012). This is particularly characteristic of the discourse of intensive parenting which, in the global North, has become the new dominant cultural script, and is no less gender-neutral than the discourse of the 'managerial university' (Douglas \& Michaels, 2004; Hays, 1996; Shirani, 2012). In the UK, parenting and other forms of care work have 
traditionally been constructed as 'private' matters. This care order is highly gendered as it is women who are expected to undertake most care work (AUTHOR). However, this view of care as private has considerably transformed under neo-liberal regimes of governmentality, which stress the importance of parental choice, yet simultaneoulsy subject parents to intense scrutiny (see for example Centre Forum, 2011, as well as the emergence of a range of provision targeting parents, such as parenting classes). Mothers, particularly working-class and single mothers, have been a key target of these neoliberal parenting policies (Gewirtz, 2001; Hinton-Smith, 2012), and are expected to dedicate considerable time and energy to raising their children (Danna Lynch, 2008; Douglas \& Michaels, 2004; Hays, 1996). The 'bottomless' nature of parenting and of academic work raises important challenges for student parents who are perceived as responsible for their 'life choices' as they operate within a 'risk and responsibility ethos' (Beck, 1992) and must reconcile two activities which, under current terms, remain little compatible due to the normative and physical dissociation of academia and care - an opposition already ingrained in Cartesian ideals, as discussed above, and reactualised through the discourses of the managerial university and of intensive parenting.

How does this dissociation from care play out in academia? In the physical and policy, offline and online spaces of UK HE, evidence of parental status and the presence of children on campus remain rather unusual occurrences. Representations of students in media, popular culture and university texts often cry out of the carefree, careless and 'irresponsible' lifestyles students are presumed to be living. University websites and prospectuses hint to the drinking and partying culture in which students are assumed to engage (Leathwood \& Read, 2009), and so do politicians (Hodge, 2002). Media accounts often purport similar views, as exemplified in the UK by a number of programmes following young people, usually university students, as they holiday abroad, as in Freshers (ITV2, 2013), or start university, as in The Secret Life of Students (Channel 4, 2014). While each of these productions takes a specific spin, they share a view of students who are enrolled fulltime, have no visible caring responsibilities, and live relatively careless and carefree lifestyles, of which clubbing, drinking, engaging in sexual activity and occasionally studying represent key components. These popular culture texts rarely acknowledge the fact that many HE students are engaged in various forms of work, as employees (AUTHOR) or as carers (NUS, 2009, 2013). Similarly, despite decades of concerns and policies for widening participation and lifelong learning (DES, 1987; DfES 2003; National Committee of Enquiry into Higher Education, 1997; Robbins, 1963), student parents and other student carers remain mostly absent from national policy discussions about widening participation or, at best, are quickly alluded to. While many student parents are mature students, these categories only partly overlap (AUTHOR). At institutional level, university documentation rarely mentions student parents, as observed during the desk phase of this study. Their existence tends to be only acknowledged in 'specific' spaces (for example, a nursery webpage or a prospectus targeting this group), which often require some investigation to be discovered. Interviews 
conducted with university staff based in Student Services also led to the identification of instances of limited awareness of the provision in place and of the presence of this group in their own institution. Provision for student parents and for their children are usually based in discrete locations often unknown to staff and childfree students, as in the case of the changing and breastfeeding rooms which some of the members of staff interviewed for this research knew existed, yet were unable to locate. Similarly, the traditional pedagogical arrangements in which students sit behind desks mean that it is possible for pregnant bodies to remain outside of the public gaze during classroom interactions. It is also common practice for institutions not to collect data based on students' family circumstances - the Higher Education Statistical Agency does not make this a compulsory requirement, in contrast with what happens in other regions of the UK (e.g., in Northern Ireland), although the Equality Challenge Unit and others have called for this to be addressed (AUTHOR; NUS, 2009; Pugh, 2010). It is also worth commenting here that issues of fertility, still births and miscarriages, which affect people's lives in multiple and often profound ways, are rarely narrated in academic contexts and, due to their invisibility, generally unsupported from within academia (Weaver-Hightower, 2012).

By rendering carers, children and pregnant bodies invisible in academia, media, national policy and university 'texts' regulate (the) student body/ies and normalise the association of the 'bachelor boy' with HE. As a result, when they become visible, parenting and pregnant bodies, which break what Hinson Shope (2005) bluntly calls the 'no-uterus rule' (2005) and Mason and Ekman (2007) the 'no children allowed' rule, risk being 'othered' or marginalised, especially as their revelation is often coincidental or even accidental, and as they concentrate among groups of students also marked as 'others', such as mature, Black and Minority Ethnic and working-class students (Baxter \& Britton, 2001; Reay, 2003; Reay et al, 2010). Indeed, parental status often comes to the attention of staff when a problem arises, meaning student parents are likely to be labelled as 'problem' students, a point discussed further elsewhere (AUTHOR). The same can be told of children, whose presence often only become visible when they come to 'disturb' the conventions of academic life. Medved recalls how, asking a question during a lecture she was delivering to 250 students, a four-year old child was the only person to raise her hand (Medved \& Heisler, 2002). As childcare arrangements had fallen through, the student had adjusted her care practice and taken her child to class, leading to a sudden hyper-visibility of her caring responsibilities. During the interviews conducted as part of the research project on which this article draws, students mentioned how they sometimes walked late in lectures and seminars for similar reasons (AUTHOR). While some revealed their motive to the relevant member of staff, others kept it to themselves, providing an illustration of the conundrum student parents face regarding the concealment or disclosure of care, as their identity as parents is not otherwise usually visible outside those 'crisis' moments. By bringing private life in academia, parenting and pregnant bodies become subversive of the public/private binary (HinsonShope, 2005; Kannen, 2013), in the same way that women entering HE before the 1950s did (Davies, 2006). It is 
worth noting that 'public' and 'private' are contestable notions, especially as, in a converging movement, public space has become increasingly commodified and private lives have become subjected to new modes of surveillance. However, while 'Pregnancy has become an increasingly «public» experience, with more visibility and acceptability of the pregnant body in public life, workplaces and the media' (Heffernan et al, 2011: 321), I argue hereafter that the visibility and acceptability of parenting and pregnant bodies depends on their social and spatial location.

An examination of the written policies and documentation made available in the ten university case studies provides some enlightening evidence regarding the invisibilisation and othering processes to which parents and children are subjected in academia. For example, attitudes to children's access to campus can vary significantly across institutions, with policies which are more or less restrictive. These restrictions can of course be interpreted as a result of a concern for health and safety, with access to areas where their presence is deemed dangerous, such as laboratories, presumably forbidden on this basis. ${ }^{5}$ However, in some cases, other motives are conjured up to justify this exclusion. In one case study, a written policy stated that, 'To minimise distraction in a learning environment, children will not be permitted to accompany adults in resource centres and classrooms where lectures and other academic activities are taking place'. In the same institution, one student had complained of being walked out of a building by a security guard because she had come accompanied by a young child, while another student complained that she had struggled to hand-in her assignment as the drop-in box outside the library building had broken down and, as a result, she needed to enter the library with her young child. In such instances, care, carers and those they care for are not simply subjected to a discourse of invisibility, they are also constructed as 'others' who do not belong in academia. Children in particular merely become an 'unfortunate interruption in the workings of a political economy' (Evans, 2013: online) - ironically, in this case, in an educational setting. This can be read as a result of the long-lived binary between the natural and emotional child and the educated and rational adult, with the former constructed as a disturbance to the later and to their learning, and with academic space constructed as 'adult space', as adults try to and usually succeed in maintaining their spatial hegemony (Valentine, 1996). The invisibility and othering to which parents and children are subjected is also part of a broader pattern of Western neoliberal societies, in which care work tends to be invisibilised, as well as unrewarded and discarded as 'niceties' (rather than 'proper' work), despite performing vital functions at societal, institutional and inter-individual level (Lynch et al, 2009; Macoun \& Miller, 2014).

\footnotetext{
${ }^{5}$ Children's exclusion from campuses may also result from the insurance policies contracted by universities. However, no information confirming that this may be the case was accessed by the research team in the ten case study institutions.
} 


\section{Who cares? Three institutional approaches to student parents}

Beyond the prevailing societal patterns discussed above, little is known about institutional variations, as most literature on the topic draw on a single case study, despite work pointing to the high level of stratification of the HE sector (Morley, 2013) and to the importance of institutional habitus (Reay et al, 2010). As in Brooks (2012), the ten institutions involved in this study were found to have significantly different approaches to student parents, depending on the level and type of provision available.

A first type of approach ('universal' or 'careblind') was typified by a minimal policy intervention. This was a prevailing pattern in two of the ten case studies conducted, which had no or very little provision in place for this group, whether in terms of a specific or mainstream intervention. Case Study 7 (a post-1992 institution located in the South of England) typifies this approach. An examination of the university website and of the policies and guidelines the research team was able to access, combined with the interviews, led to the identification of a prevailing discourse of invisibility as far as student parents were concerned. No policy or provision targeting student parents was in place, whether in the form of a specific provision or of the mainstreaming of care in generic policies. A rare and quick reference to student parents was found in the guidance notes for claiming extenuating circumstances, which mentioned childbirth, pregnancy complications and the serious illness of a relative (including a child) among other eligibility criteria. The health and safety and the library policies mentioned children, but only to forbid their presence on most premises or to allow it under strict conditions (i.e., occasionally and for brief periods of time, to deliver or collect study-related materials).

In a second approach ('targeted'), some specific provision was made available for student parents. This approach characterised five universities. This group represented a very diverse sample, both in terms of their characteristics and of the extensiveness and nature of their policy intervention in this area. Case Study 3 (a pre-1992 institution based in the Midlands) illustrates this approach. The university website and documentation made some reference to student parents, though mostly in the nursery section. Two nurseries were based on campus, one of which run by the university. Other available provision included: a means-tested grant to support students with childcare, a unit specifically dedicated to childcare services within Student Services, a play centre for toddlers up to school age, a school holiday play scheme, and a toy loan service.

In a third approach ('mainstreaming'), the specific provision in place was associated with some attempts to mainstream the needs of student parents into policies. Three universities fell predominantly into this category. Of the ten participating institutions, Case Study 1 (a post-1992 
institution located in the South of England) offered the most integrated provision in relation to student parents. The university website and other documentation provided some extensive references to student parents. The provision in place was also extensive compared with other universities and included two university-run nurseries, for 2-5 year old children, with discounted fees for student parents and a high level of flexibility in the choice of childcare sessions. The university also allowed children and babies on campus, with the exception of areas deemed high risk (such as science laboratories), including in lectures and seminars where this was however subject to the approval of the lecturer. Spaces were dedicated to student parents, who also had established their own meeting group. An equality adviser ensured that student parents' perspectives were acknowledged across the board and that parenting issues were mainstreamed, and also provided one-to-one support to members of this group. Following a consultation with student parents, two comprehensive sets of guidelines for students with dependants and for staff dealing with this group had been developed. These guidelines recommended a high level of policy mainstreaming in relation to this group, for example requesting adjustments in relation to teaching arrangements, health and safety issues, timetabling, applying for mitigating circumstances, study options, and access to various forms of support.

It is important to note here that the distribution of the case studies across the three approaches is unlikely to be representative of what happens sector-wide. Indeed, this research sought to recruit a sample of institutions as diverse as possible (as detailed in the Methodology section) to facilitate the identification of a range of approaches to student parents, rather than a representative sample from which findings could be generalised. In all likeliness, universities with the most advantageous provision are over-represented in this study, as it became evident when negotiating institutional access that those willing to be involved often had a pre-existing interest in this area. Similarly, while student parents based in the universities with the most generous provision tended to express the higher levels of satisfaction about being a student parent, no claim is made here of a simplistic, causal correspondance between the two. In addition, it is important to note that some universities may tipify a specific type of approach, yet higher education institutions are complex environments rather than unified entities and always present some level of hybridity in their approaches to student parents (Marandet \& Wainwright, 2009).

These approaches have various implications for student parents. The first and second approaches provide a vivid illustration of how policies which are apparently neutral can contribute to the othering of student parents (rather than grant them fully-fledged academic citizenship) and to the establishment of care regimes which are geared towards childfree students. As generic policies are usually designed with the childfree student in mind, their negative effects on parents, including en-at academic, financial, social, health and emotional levels, risk being overseen (AUTHOR). This is exemplified by the institutional policies which regulate the working of universities on a spatio- 
temporal level. Research on student parents has evidenced the centrality of spatio-temporal conflicts in the narratives of student parents as they juggle the discordant demands and time frames of two 'greedy institutions' (see, e.g., Brooks, 2013; Danna Lynch, 2008; AUTHOR). In particular, university timetabling policies were deemed to be very problematic by the students interviewed as part of the original study on which this article draws, as the timing of some lectures and seminars (e.g., early morning, evening and week-end) created some discordance with other commitments (Alsop et al, 2008), particularly for single student parents who could not rely on the support of a partner (HintonSmith, 2012). Similarly, many students received their timetable too late to be able to secure appropriate childcare (see also Alsop et al, 2008). The following quotes are typical of the issues timetabling policies can generate for students with caring responsibilities. Although these policies are thought of as 'neutral' in terms of their effects on students as they are presumed to address the needs of the 'universal' student, it is only those needs of the 'bachelor boy' which they address.

They gave me the timetable on the day I started, and I said, 'how can I organise childcare?'. I couldn't organise anything because they wouldn't give us the timetable. Then I was the student rep for last year and I brought it up... So we had it... three weeks early this year. But three weeks still isn't enough, not for childcare. (Elizabeth, Case Study 8)

As I am walking in [at] 9.20am after dropping the kids off, you can sense or there is often a comment that lecture starts at 9am. But you can't go wailing in saying, 'but I've got kids.' It doesn't seem very supportive, so I choose not to stroll in at that time because it is highly embarrassing when a lecturer embarrasses you in front of 150 other students telling you what time it is. (Shanice, Case Study 7)

Such policies can lead to feelings of injustice and frustration, as student parents feel that they are expected to fit in a rather rigid cultural frame which puts them at a disadvantage and requires that they adjust their parenting and other care practices, as the following extract illustrates.

... it is certainly not unheard of that they put a lecture on and say you will be in at nine o'clock tomorrow and you get the email at five o'clock the night before... If you are young, free and single maybe you can cope with that, but even then maybe you'd have plans. (Holly, Case Study 7)

Like 'time policies', 'space policies' can regulate which bodies belong in academia, as noted earlier about policies regulating access to campus or, for example, when student parents have to use unsuitable spaces (e.g.- a lavatory) for baby change or to extract milk. However, aspects of university cultures which are not formalised into written policy statements can have similar effects to formal institutional policies. For example, research students are usually expected to attend research seminars and social events. It is not uncommon for these to take place at the end of the day, with-resulting in potential conflicts with family commitments. Ultimately, this can mean missing out on the benefits associated with such events, in terms of learning and intellectual development, of future employment 
opportunities and of wider networking and support within their community of practice. This, combined with other aspects of academic cultures, can also reinforce a sense of 'not belonging'. As one student put it,

An awful lot of conversations that are relevant to my research happens... after hours in the student pub where my department meet. They always meet there after 5 pm everyday and I can never go and I miss out on a lot of talk about conferences that are coming up and papers that have been published and possible collaborations. I miss all of that which can make it a bit harder because I don't know who is doing what research, which makes it a lot more difficult to collaborate. (Nabila, Case Study 2)

Despite seemingly addressing the needs of the 'universal' student, Both-approach 1 and 2 are characterised by a prevailing approach which, despite seemingly addressing the needs of the 'universal' student, actually normalise the experience of childfree students and position their parenting counterparts as others. However, in contrast with approach 1, approach 2 appears less 'careblind' as it offers some provision targeting student parents. While the nature and extent of such provision varies considerably across institutions, childcare often constitutes a pivotal element of these specific policies and one which, in our study and in the work of others, has been identified as having the most positive effect on student parents (see, e.g., Institute for Women's Policy Research, 2010). ${ }^{6}$

This specific or 'targeted' approach to student parents is not, however, without its limitations. First, the provision is often under-resourced. For example, while student parents who participated in the original study on which this paper draws usually paid a discounted fee for their use of the services of a university nursery, the fees remained high. ${ }^{7}$ Supply often did not meet demand. As one student commented, 'I don't use them on our campus, because when I first applied we had to go on a waiting list and I couldn't wait' (Tahera, Case Study 6). Financial support such as the Childcare Grant is not accessible to part-time, postgraduate and international students - all groups among whom student parents concentrate. The low levels of financial support (with the exception of the Childcare Grant), combined with procedures often described as complex and time-consuming mean that even student parents who are eligible may not apply to receive financial support. Second, while the development of some specific provision for student parents means that universities acknowledge the needs of this group, other ('universal') policies are left untouched despite being modelled around the needs of 'traditional' (i.e. childfree) students (Marandet \& Wrainwright, 2010). Thus, 'targeted' policies can have limited or even counterproductive effects in way of challenging the default construction of the 'bachelor boy'. While the benefits for the student parents accessing the provision should not be dismissed, this 'add on' approach is underpinned by a view of this group as 'special', which risks in

\footnotetext{
${ }^{6}$ For a more comprehensive overview of institutional policies targeting student parents and of their effects on this group, see AUTHOR.

${ }^{7} \mathrm{It}$ is worth reminding here that England currently has some of the highest tuition fees and childcare provision in the world, thus a minimal discount is unlikely to have a significant effect on students' finances.
} 
turn to lead to its construction as 'costly', 'demanding' or 'needy'. ${ }^{8}$ This deficit discourse of student parents is also evidenced by the fact that this 'specific' approach usually targets students rather than their environment and those with whom they interact in HE.

In some of the case study institutions, attempts were made to adopt a more mainstream approach to care in academia. This approach has been mobilised since the mid-1990s across the global North and represents a key element of the European Commission's strategy to tackle specifically gender inequalities (European Commission, 2000). It remains a 'contested concept and practice' (Walby, 2005: 321), although the definition given by the Council of Europe of the concept ('the (re)organisation, improvement, development and evaluation of policy processes, so that a gender equality perspective is incorporated in all policies at all levels and at all stages, by the actors normally involved in policy-making'-1998, cited in Verloo, 2001: 2) has been broadly adopted. Compared with other strategies, this approach presents a number of benefits. As well as being rather effective in pushing gender issues (since gender has usually been the target of mainstreaming) on policy agendas (Verloo, 2001), it potentially acknowledges the careblind and biased character of 'universal' policies. As argued by Verloo, 'The underlying assumption is that most regular policies are gendered, that regular policies are a major constitutional element in the construction of gendered social institutions, and that gendered social institutions are an important component in the continuous reconstruction of gender inequality' (ibid.: 2). This approach also shies away from a deficit perspective of student parents and other groups experiencing inequalities, thanks to its recognition of the systemic dimension of the issues they face.

Thus, the mainstreaming of care (and other equality matters) across HE has the potential to challenge the default construction of the 'bachelor boy' as the (ideal) student and the related construction of the student parent as 'special', 'demanding' or 'needy', as care and support to carers ideally become systematically embedded in policies and practices and normalised. This point is also made by Clegg et al, who argue that 'What is needed are mainstream pedagogic practices that will enable [students] to have productive encounters with the challenging realities of learning' (2006: 112). This systematic approach also implies that policy intervention does not solely target (and single out) student parents. An example of this was provided by Case Study 1, discussed above, in which guidelines for students with dependants and for staff dealing with this group had been developed. In other countries, such as the US, awareness training of staff in relation to student parents is not uncommon (Swingle, 2013), although it was nonexistent in our sample. In that respect, the mainstreaming of care could be described as a more radical approach to equality matters as it tackles the cultures and structures of institutions, compared with the more liberal-leaning 'universal' and

\footnotetext{
${ }^{8}$ While this paper does not focus on this aspect, it was indeed the case that some staff held such negative views of student parents (see AUTHOR).
} 
targeted approaches which, in England, have traditionally typified institutional takes on non traditional students (Marandet \& Wainwright, 2009).

However, mainstreaming also presents some caveats. First of all, to be effective, such a strategy needs to be well-resourced and implemented in a systematic way across the institution, something which does not appear to be the case in any of the ten universities involved in this study. Second, it also needs to become a collective project to which all subscribe. Otherwise, mainstreaming risks resulting in solely performative documents (Tlili, 2007) whose objectives are resisted by those in charge of implementing them. Third, this approach risks 'diluting' equality issues and getting them out of sight, as these come to be seen as 'the responsibility of everyone' (Verloo, 2001: 8). For these reasons, there appears to be a need for a member of staff or a committee to retain ownership of the policy, with responsibility for pushing forward the equality agenda and overseeing policies and their effects on student parents. Last, while part of the appeal of gender mainstreaming has been linked to its feminist and transformative potential, this potential can easily be lost. This point is made by Phipps (2006) who, drawing on the case of the European Commission's gender mainstreaming policy, claims that the implantation of mainstreaming in marketised, neo-liberal policy agendas and the precedence given to economic goalstakes over equality matters have eroded its radical edge.- Case Study 1 provides a vivid illustration of such challenges: despite the best efforts of the equality officer and of her colleagues to mainstream care issues in the university culture and policies, at the same time, the university nurseries were threatened with closure.

\section{Conclusion}

The relationship between care and academia is fraught with tensions, which come to the fore as students with caring responsibilities (in this case, student parents) enter academia and become a significant presence on campuses across England and other parts of the global North (Johnson et al, 2009; NUS, 2009). Drawing on sociological understandings of work and education informed by feminist theories, this paper highlights how institutions regulate (the) student body/ies through policies which position care outside or at the margins of $\mathrm{HE}$ and in some instances expect all students to adopt the identity of the disembodied universal learner (in reality a male, White, middle-class, childfree learner in disguise) (Leathwood \& O'Connell, 2003; Leathwood \& Read, 2009; Maher \& Tetreault, 2007). Thus, the acceptance of parenting 'others' is always conditional and relies on the denial of corporeality and care.

The student population has considerably changed overtime. However, the persistence of the Cartesian dualisms which have shaped modern science and knowledge production sites (Descartes, 1996 [1641]), actualised through highly gendered discourses of the managerial (and careless) 
university, continues to favour the linkage of the 'bachelor boy' (Edwards, 1993; Hinton-Smith, 2012) with academic excellence, and the production of 'care regimes' which are overall unfavourable to student parents. Once excluded, student parents have now gained access to the margins of academia. However, while stastistical data on this group remain scarce, the fall in the recent years in numbers of part-time and mature students (HEPI, 2013), among which student parents concentrate, suggests that exclusion and marginalisation are both ongoing concerns.

Overall, the presence of student parents and of signifiers of parenting on campus remains discreet, even hidden: parenting in academia keeps on being one of these 'unspeakable things unspoken' (Morrisson, 1989: 3), a personal matter kept invisible in academic circles yet always on the brink of being made hyper-visible (Spack, 1997). Children, parenting and pregnant bodies are the 'ousider-within' (Collins, 2000), the 'space invaders' (Puwar, 2004) who disturb the binaries between care and academia, public and private, body and mind. The belonging of student parents in academia is further complicated by their positioning as members of other dominated groups among which they are more likely to concentrate than their childfree counterparts. In the context of an increased discursive individualisation of the social, this 'politics of misrecognition in which the other is excluded, marginalized and often subjected to ridicule, derision, shame or symbolic violence' (Burke $\&$ Crozier, 2014: 57) can lead to feelings of shame and guilt discussed elsewhere (AUTHOR; see also Brooks, 2015).

The 'striking lack of policy attention to the integration of non-traditional students in higher education' noted by Marandet and Wainwright (2009: 110) at national level is also a widespread pattern of institutional policies, as far as student parents are concerned. However, beyond the broad sectorial patterns discussed above, approaches to student parents vary across institutions, highlighting the relevance of the multi-level approach to inequalities adopted in this paper (Crompton et al, 1999). Three prevailing approaches were identified, echoing in this earlier distinctions of policy approaches to equality (e.g., Fraser, 1997, and, in relation to student parents, Marandet \& Wright, 2009). A first ('universal') approach is typified by a minimal intervention in direction of student parents. This approach may be perceived as providing equal opportunities through the same treatment of student parents and of their childfree couterparts. However, institutional policies constructed as 'universal' and 'neutral' are in reality geared towards childfree students, with, as a result, student parents having to adjust their care practices to fit in. In a second ('targeted') approach, some specific provision is made available for this group. This approach can have a positive effect on those with access to the appropriate resources (AUTHOR; Springer et al, 2009; Swingle, 2013). However, while targeted policies bring some visibility and support for those with caring responsibilities, this approach simultaneously risks reproducing a deficit view of this group as 'special' or 'needy'. In other words, such an 'add on' approach- does not lead to a significant rethinking of higher education to reflect 
changes in the student composition (Marandet \& Wainwright, 2009). In a third ('mainstreaming') approach, attempts were made to mainstream the needs of student parents in academia. This approach echoes Marandet and Wright's (2009) identification of a transformative discourse, which constructs all students as potential caregivers, and Fraser's (1997) utopian universal caregiver model. Through its acknowledgement of the role that university policies play in compounding the problems faced by student parents and its call for a more systemic solution, this approach ultimately shies away from a deficit perspective (Verloo, 2001).

However, to be effective, mainstreaming needs to be well-resourced, deeply ingrained in institutional cultures, and to become a collective project to which all subscribe. This is not without challenges in a context in which care is constructed as a personal, private and female matter and in which the neo-liberal principles that drive policy-making are only favourable to carers when it meets economic imperatives. While the boundaries between care and academia have become porous and care in academia a contested ground (see for example the Save the Nurseries campaign, run by NUS, with UCU and UNISON), so called austerity budgets, as well as a sharp rise in university fees and the closure of many university nurseries and other support services mean that this endeavour is more important than ever. Like widening participation, care remains 'an unstable project against a backdrop of aggressive neoliberal measures' (Burke, 2013: 108). This calls for further deconstruction of the pervasive ways privilege and power operate in academia.

8,313 words (abstract and references not included, footnotes included)

\section{Acknowledgements}

\section{References}

Ahmed, S. (1998) Differences that matter: feminist theory and postmodernism (Cambridge, Cambridge University Press).

Alsop, R., Gonzalez-Arnal, S. \& Kilkey, M. (2008) The widening participation agenda: the marginal place of care, Gender \& Education, 20(6), 623-37.

Archer, L., Hutchings, M. \& Ross, A. (2003) Higher education and social class: issues of exclusion and inclusion (London, RoutledgeFalmer). 
Armato, M. (2013) Wolves in sheep's clothing: men's enlightened sexism and hegemonic masculinity in academia, Women's Studies: An Interdisciplinary Journal, 42(5), 578-598.

Bates, L. (2014) Ten things female students shouldn't have to go through at university. The Guardian, Available online at: http://www.theguardian.com/lifeandstyle/womens-blog/2014/oct/10/10things-female-students-face-university-misogyny-banter (accessed 15 June 2015).

Baxter, A. \& Britton. C. (2001) Risk, identity and change: becoming a mature student, International Studies in Sociology of Education, 11(1), 87-104.

Beard, C., Clegg, S. \& Smith, K. (2007) Acknowledging the affective in higher education, British Educational Research Journal, 33(2), 235-252.

Beck, U. (1992) Risk Society: towards a new modernity (London, Sage).

Bordo, S. (1987) The flight to objectivity: essays on Cartesianism and culture (NYC, State University of New York Press).

Bowles, G. \& Duelli-Klein, R. (Eds.) (1983) Theories of women's studies (Berkeley, University of California Press).

Braidotti, R. (1991) Patterns of dissonance: an essay on women in contemporary French philosophy (Cambridge, Polity Press).

Brooks R. (2015) Social and spatial disparities in emotional responses to education: feelings of 'guilt' amongst student-parents, British Educational Research Journal, 41(3), 505-519.

Brooks, R. (2013) Negotiating time and space for study: student parents and familial relationships, Sociology, 47 (3), 443-459.

Brooks, R. (2012) Student-parents an, higher education: a cross-national comparison, Journal of Education Policy, 27 (3), 423-439.

Burke, P.J. (2013) The right to higher education: neoliberalism, gender and professional mis/recognitions, , International Studies in Sociology of Education, 23(2), 107-126.

Burke, P.J. \& Crozier, G. (2014) Higher education pedagogies: gendered formations, mis/recognition and emotion, Journal of Research in Gender Studies, 4(2), 52-67.

Calvert, M., Lewis, T. \& Spindler, J. (2011) Negotiating professional identities in higher education: dilemmas and priorities of academic staff, Research in Education, 86(1), 25-38.

Channel 4 (2014). The Secret Life of Students (London, Channel 4 Production).

Clegg, S., Bradley, S. \& Smith, K. (2006) 'I've had to swallow my pride': help seeking and selfesteem, Higher Education Research \& Development, 25(2), 101-113. 
Collins, P. (2000) Black Feminist thought (New York, Routledge).

Coser, L. (1974) Greedy institutions (New York, Free Press).

Crompton, R. (ed.) (1999) Restructuring gender relations and employment: the decline of the male

Breadwinner (Oxford, Oxford University Press).

Crozier, G., Reay, D. Clayton, J. \& Colliander, L. (2008) Different strokes for different folks: diverse students in diverse institutions - experiences of higher education, Research Papers in Education, 23(2), 167-177

Danna Lynch, K. (2008) Gender roles and the American academe: a case study of graduate student mothers, Gender \& Education, 20(6), 585-605.

David, M., Edwards, R., Hughes, M. \& Ribbens, J. (Eds.) (1993) Mothers and education: inside out? Exploring family-education policy and experience (Basingstoke, The Macmillan Press).

Davies, B. (2006) Women and transgression in the halls of academe, Studies in Higher Education, 4, 497-505.

Delphy, C. (2010) Un universalisme si particulier: féminisme et exception française 1980-2010 (Paris, Syllepse).

DES (1987) Higher education: meeting the challenge (London, HMSO).

Descartes, R. (1996) Meditations on first philosophy (Cambridge, Cambridge University Press) [Original work published in 1641].

DfES (2003) The future of higher education. Government White Paper (London, DfE).

Douglas, S. \& Michaels, M. (2004) The mommy myth: the idealization of motherhood and how it has undermined women (New York, Free Press).

Edwards, R. (1993) Mature women students: separating or connecting family and education (London, Taylor \& Francis).

Ellis-Petersen, H. (2014) London School of Economics disbands men's rugby club over misogynist leaflet. The Guardian. Available online at: http://www.theguardian.com/education/2014/oct/07/london-school-economics-lse-disbandsrugby-club-misogynist-leaflet (accessed 15 June 2015)

European Commission (2009) She figures 2009: statistics and indicators on gender equality in science (Brussels, European Commission).

European Commission (2000) Science policies in the European Union. Promoting excellence through mainstreaming gender equaliy. Rapport du groupe ETAN, Expert Working Group on Women 
and Science (Brussels, European Commission).

Evans, M. (2013) Regarding young children as an unfortunate interruption in the workings of a political economy radically disregards the building bricks through which a society is constructed British Politics and Policy at LSE. Blog entry, 9 December 2013. Available online at: http://blogs.lse.ac.uk/politicsandpolicy/archives/38260 (accessed 15 September 2015).

Foucault, M. (1969) L'archéologie du savoir (Paris, Gallimard).

Fraser, N. (1997) After the family wage: a post industrial thought experiment', in: N. Fraser (ed.) Justice interruptus: critical reflections on the 'postsocialist' conditions (London, Routledge).

Fraser, N. \& Gordon, L. (1997) A genealogy of 'dependency', in: N. Fraser (ed.) Justice interruptus: critical reflections on the 'postsocialist' condition (New York, Routledge).

Freire, P. (1972) Pedagogy of the oppressed (Harmondsworth, Penguin Books)

Gerwirtz, S. (2001) Cloning the Blairs: New Labour's programme for the re-socialization of working class parents, Journal of Education Policy, 16(4), 365-78.

Gill, R. (2009) Breaking the silence: the hidden injuries of neo-liberal academia, in: Flood, R. \& Gill, R. (Eds.) Secrecy and silence in the research process: Feminist reflections (London, Routledge).

Grummell, B., Devine, D. \& Lynch, K. (2009) The careless manager: Gender, care and new managerialism in higher education, Gender and Education, 21(2), 191-208.

Hays, S. (1996) The cultural contradictions of motherhood (New Haven, CT, Yale University Press).

Heffernan, K., Nicolson, P. \& Fox, R. (2011) The next generation of pregnant women: more freedom in the public sphere or just an illusion?, Journal of Gender Studies, 20(4), 321-332.

Héritier, F. (2002) Masculin/féminin II. Dissoudre la hiérarchie (Paris, Odile Jacob).

Hinton-Smith, T. (2012) Lone parents' experiences as higher education students (Leicester, NIACE).

Hinson Shope, J. (2005) Reflections on the no-uterus rule: pregnancy, academia, and feminist pedagogy, Feminist Teacher, 16 (1), 53-60.

HEPI (2013) The impact on demand of the Government's reforms of higher education (Oxford, HEPI).

Hodge, M. (2002) Examination of witness, question 263 (London, House of Commons Select Committee on Education \& Skills).

hooks, B. (1994) Teaching to transgress: education as the practice of freedom (New York, Routledge).

ITV2 (2013) Freshers (London, ITV2 Productions/Mentorn Media). 
Johnson, C., Pollard, E., Hunt, W., Munro, M., Hillage, J., Parfrement, J. \& Low, N. (2009) Student income and expenditure survey 2007/08: English-domiciled students. DIUS Research Report 09-05. (Brighton, Institute for Employment Studies).

Kannen, V. (2013) Pregnant, privileged and PhDing: exploring embodiments in qualitative research, Journal of Gender Studies, 22(2), 178-191

Le Feuvre, N. (ed.) (2002) Le genre: de la catégorisation du sexe (Toulouse, UTINAM-L'Harmattan).

Leathwood, C. \& V. Hey (2009) Gender(ed) discourses and emotional sub-texts: theorising emotion in UK higher education, Teaching in Higher Education, 14 (4), 429-440.

Leathwood, C. \& O'Connell, P. (2003) 'It's a struggle': the construction of the 'new student' in higher education, Journal of Education Policy, 18(6), 597-615.

Leathwood, C. \& Read, B. (2009) Gender and the changing face of higher education: a feminised future? (Buckingham, SRHE \& Milton Keynes, Open University Press).

Lécuyer, C. (2005) Une nouvelle figure de la jeune fille sous la IIIe République : l'étudiante, Clio, 4. Available online at: http://clio.revues.org/index437.html (accessed on: 15 July 2011).

Lloyd, G. (1993) The man of reason: 'male' and 'female' in Western philosophy (London, Routledge).

Lynch, K. (2010) Carelessness: a hidden doxa of higher education, Arts and Humanities in Higher Education, 9(1), 54-67.

Lynch, K. (2006) Neo-liberalism and marketisation: the implications for higher education, European Educational Research Journal, 5 (1), 1-17.

Lynch, K., Baker, J., and Lyons, M. (2009) Affective equality: love, care and injustice (Basingstoke, Palgrave Macmillan).

Macoun, A. \& Miller, D. (2014) Surviving (thriving) in academia: feminist support networks and women ECRs, Journal of Gender Studies, 23(3), 287-301

Maher, F. A. \& Tetreault, M. K. T. (2007) Privilege and diversity in the academy (New York, Routledge).

Marandet, E. \& Wainwright, E. (2010) Invisible experiences: understanding the choices and needs of university students with dependent children, British Educational Research Journal, 36(5), 787-805.

Marandet, E. \& Wainwright, E. (2009) Discourses of integration and exclusion: equal opportunities for university students with dependent children?, Space and Polity, 13(2), 109-125.

Mason, M.A. \& Ekman, E. (2007) Women on the fast track (New York, OUP). 
Matthews, J. (1984) Good and mad women: the historical construction of feminity in twentieth-century Australia (Sidney, Allen and Unwin).

Medved, C. E. \& Heisler, J. (2002) A negotiated order exploration of critical student-faculty interactions, Communication Education, 51(2), 105-120.

Morley, L. (2013) The rules of the game: women and the leaderist turn in higher education, Gender \& Education, 25(1), 116-131.

Morley, L. \& Walsh, V. (Eds.) (1996) Breaking boundaries: women in higher education (London, Taylor \& Francis).

National Committee Of Enquiry Into Higher Education (1997) Higher education in the learning society: The Dearing Report (London, HMSO).

Nikunen, M. (2014) The 'entrepreneurial university', family and gender: changes and demands faced by fixed-term workers, Gender and Education, 26(2), 119-134.

NUS (2013) Learning with care (London, National Union of Students).

NUS (2009) Meet the parents: the experience of students with children in further and higher education (London, National Union of Students).

Office for National Statistics (2013) Full report: graduates in the UK Labour Market 2013 (London, ONS).

Olssen, M. \& Peters, M. (2005) Neoliberalism, higher education and the knowledge economy: from the free market to knowledge capitalism, Journal of Education Policy, 20(3), 313-345.

Phipps, A. (2006) 'I can't do with whinging women!' Feminism and the habitus of 'women in science' activists, Women's Studies International Forum, 29 (2), 125-135.

Pugh, E. (2010) Student pregnancy and maternity: implications for higher education institutions (London, Equality Challenge Unit).

Puwar, N. (2004) Space invaders: race, gender and bodies out of place (Oxford, Berg).

Read, B., Archer, L. \& Leathwood, A. (2003) Challenging cultures? Student conceptions of 'belonging' and 'isolation' at a post-1992 university, Studies in Higher Education, 28(3), 261277.

Reay, D. (2003) A risky business? Mature working-class women students and access to higher education, Gender \& Education, 15(3), 301-317.

Reay, D. (2000) 'Dim dross': marginalised women both inside and outside the academy, Women's Studies International Forum, 23 (1), 13-21 
Reay, D., Crozier, G. \& Clayton, J. (2010) 'Fitting in' or 'standing out': working class students in UK higher education, British Educational Research Journal, 36(1), 107-124

Riley, K. (1994) Quality and equality: promoting opportunities in schools (London, Cassell).

Robbins, B.L. (1963) Higher education report of the Committee on Higher Education, 1961-63 (London, HMSO).

Rossiter, M. (1982) Women scientists in America: struggles and strategies to 1940 (Baltimore and London, Johns Hopkins University Press).

Savigny, H. (2014) Women, know your limits: cultural sexism in academia, Gender \& Education, 26(7), 794-809.

Schell, E. (2002) Feminist un/motherhood: reigning rhetorics of parenting inside and outside of academe, $J A C$ (Fall issue), 404-413.

Schiebinger, L. (1992) Women in science: historical perspectives, in: C. Urry, M. Danly, L.E. Sherbert $\&$ S. Gonzaga (eds) Women at work: a meeting on the status of women in astronomy. Meeting held at the Space Telescope Science Institute Baltimore, 8-9 September 1992

Shavit, Y., Arum, R. \& Gamoran, A. (Eds) (2007) Stratification in higher education: a comparative study (Palo Alto, CA, Stanford University Press).

Shirani, F., Henwood, K. and Coltart, C. (2012) Meeting the challenges of intensive parenting culture: gender, risk management and the moral parent, Sociology, 46 (1), 27-42.

Spack, R. (1997) The (in)visibility of the persona(al) in academe, College English, 59(1), 9-31.

Springer, K. W., Parker, B. K. \& Leviten-Reid, C. (2009) Making space for graduate student parents: practices and policies, Journal of Family Issues, 30(4), 435-457.

Swingle, A. (2013) College student parents: stress, role conflict, and coping (Indiana, Indiana University of Pennsylvania).

Tlili, A. (2007) Rendering equality and diversity policies in UK higher education institutions, Critical Discourse Studies, 4(3), 283-310

Valentine, G. (1996) Children should be seen and not heard: the production and transgression of adults' public space, Urban Geography, 17(3), 205-220.

Verloo, M. (2001) Another velvet revolution? Gender mainstreaming and the politics of implementation, IWM Working Paper No. 5/2001 (Vienne, Institut des Sciences Humaines).

Walby, S. (2005). Comparative gender mainstreaming in a global era, International Feminist Journal of Politics, 7(4), 453-470. 
Walkerdine, V. (1998) Counting girls out (London, Falmer).

Weaver-Hightower, M. (2012) Waltzing Matilda: an autoethnography of a father's stillbirth, Journal of Contemporary Ethnography, 41(4), 62-491.

Webb, S. (1997) Alternative students? Conceptualizations of difference, in: J. Williams (ed.) Negotiating access to higher education: the discourse of selectivity and equity (Buckingham, Open University Press).

Wennerås C. \& Wold A. (1997) Nepotism and sexism in peer review, Nature, 347, 341-343.

Young-Powell, A. (2014) First-year students 'encouraged to sing necrophiliac chant' by union reps. The Guardian. Available online at: http://www.theguardian.com/education/2014/oct/08/freshersstudents-sing-necrophiliac-sexist-violent-chant (acccessed 15 June 2015) 